\title{
Near-infrared fluorescent imaging with indocyanine green in rabbit and patient specimens of esophageal cancer
}

\author{
Jiyun Rho ${ }^{1,2 \#}$, Yu Hua Quan ${ }^{1,2 \#}$, Byeong Hyeon Choi ${ }^{1,2}$, Kook Nam Han ${ }^{2}$, Beop-Min Kim ${ }^{3}$, Young Ho Choi ${ }^{2}$, \\ Hyun Koo Kim ${ }^{1,2}$
}

${ }^{1}$ Department of Biomedical Sciences, College of Medicine, Korea University, Seoul, South Korea; ${ }^{2}$ Department of Thoracic and Cardiovascular Surgery, Korea University Guro Hospital, College of Medicine, Korea University, Seoul, South Korea; ${ }^{3}$ Department of Interdisciplinary Bio/Micro Technology, College of Engineering, Korea University, Seoul, South Korea

Contributions: (I) Conception and design: HK Kim; (II) Administrative support: HK Kim; (III) Provision of study materials or patients: HK Kim, KN Han, BM Kim, YH Choi; (IV) Collection and assembly of data: J Rho, YH Quan, BH Choi; (V) Data analysis and interpretation: J Rho, YH Quan, HK Kim; (VI) Manuscript writing: All authors; (VII) Final approval of manuscript: All authors.

\#These authors contributed equally to this work.

Correspondence to: Hyun Koo Kim, MD, PhD. Department of Thoracic and Cardiovascular Surgery, Korea University Guro Hospital, Korea University College of Medicine, 148, Guro-dong-ro, Gu-ro-gu, Seoul 08308, South Korea. Email: kimhyunkoo@korea.ac.kr.

Background: We aimed to assess the possibility of detecting esophageal cancer after intravenous injection of indocyanine green (ICG) in preclinical and clinical models.

Methods: Forty-five rabbits were surgically implanted with VX2 tumors into the esophageal muscular layer 2 weeks before esophagectomy. The rabbits received intravenous injection of ICG at doses of 1, 2, or $5 \mathrm{mg} / \mathrm{kg}$ at 3, 6, 12, 24, or $48 \mathrm{~h}$ before surgical removal of esophagus. Twelve patients scheduled to undergo esophagectomy were also enrolled, and all received $2 \mathrm{mg} / \mathrm{kg}$ of ICG intravenously at 3, 6, 12, or 24 h before surgical removal of esophagus. The fluorescence intensity was measured in all resected specimens from the rabbits and patients using a near-infrared (NIR) fluorescence imaging system after surgery.

Results: Esophageal tumors were successfully established in all rabbits, and fluorescent signals were detected in all animal and patient specimens. Tumor-to-normal ratio (TNR) analysis showed that higher doses resulted in a greater TNR. Injection of at least $2 \mathrm{mg} / \mathrm{kg}$ of ICG was required for clear visualization of the tumor, and the TNR was highest at $12 \mathrm{~h}$ after injection. The TNR in patients was also highest at $12 \mathrm{~h}$ $(\mathrm{P}=0.0004)$, with $2 \mathrm{mg} / \mathrm{kg}$ of ICG. None of the patients had major complications following ICG injection.

Conclusions: NIR fluorescence imaging can be used to visualize esophageal cancer after systemic injection of ICG. ICG at $2 \mathrm{mg} / \mathrm{kg}$ at $12 \mathrm{~h}$ is optimal for tumor detection. However, since the clinical trials were conducted in a small number of patients, further studies are needed in larger populations.

Keywords: Esophageal cancer; indocyanine green (ICG); translational research

Submitted May 07, 2021. Accepted for publication Oct 11, 2021.

doi: $10.21037 /$ jtd-21-790

View this article at: https://dx.doi.org/10.21037/jtd-21-790

\section{Introduction}

The use of minimally invasive surgery (MIS) for the treatment of various types of solid cancers has increased in recent years because it offers several advantages over traditional open surgery. MIS can reduce postoperative complications, shorten the hospitalization period, reduce pain, and produce better cosmetic results in terms of postoperative surgical scars (1). Open surgery involves making a large incision and allows palpation of the cancer to distinguish it from normal tissue by direct touching with the hand and observation by eye. Conversely, MIS involves a smaller incision size at the surgical site and uses endoscopes or surgical instruments to perform operations, so there are limitations in direct palpation and careful observation (2). 
Image-guided surgery using near-infrared (NIR) fluorescent imaging with indocyanine green (ICG) has been improved to visualize cancer during MIS and overcome the limitations of MIS (3). In 2009, intravenous injection of ICG was used for the first time to detect hepatocellular carcinoma (HCC) during surgery with NIR fluorescent imaging (4). After this study, NIR fluorescent imaging using intravenously injected ICG has been used in various types of tumors for nephrectomy (5) and breast cancer surgery $(6,7)$. In the field of thoracic cancer surgery, lung cancer (8), mediastinal tumors (9), and pleural mesothelioma (10) can be detected using $5 \mathrm{mg} / \mathrm{kg}$ of ICG intravenously injected $24 \mathrm{~h}$ prior to surgery using NIR fluorescent imaging. We have previously reported the identification of pulmonary neoplasms with a low dose $(1 \mathrm{mg} / \mathrm{kg})$ of intravenously injected ICG 1 day before surgery using NIR fluorescent imaging system (11). However, the detection of esophageal tumors by intravenous injection of ICG has not yet been reported.

This study aimed to evaluate, for the first time, the possibility of detecting esophageal tumors using fluorescent images with intravenous injection of ICG in an $e x$ vivo specimens. We also aimed to optimize the timing and dosage of ICG injection for esophageal tumors through preclinical and clinical studies.

We present the following article in accordance with the STROBE and ARRIVE reporting checklists (available at https://dx.doi.org/10.21037/jtd-21-790).

\section{Methods}

\section{Animals}

A total of 45 female New Zealand White rabbits weighing between 2.5 and $3.0 \mathrm{~kg}$ were used in this study. The animals were purchased from Doo Yeol Biotech in South Korea and they were housed in a metallic rabbit cage each. They also maintained under controlled temperature, humidity, and illumination. Food and water were provided freely. All animal experiments and protocols were approved by the institutional animal care and received committee approval from Korea University (KOREA-2016-0224).

\section{Esophageal rabbit tumor model}

VX2 carcinoma harvest was performed as previously described (12). VX2 carcinoma were cut into small fragments, filtered with a $100-\mu \mathrm{m}$ cell strainer, centrifuged at 1,500 $\mathrm{rpm}$ for $3 \mathrm{~min}$ at room temperature, and resuspended in phosphate buffered saline with a concentration of $1 \times 10^{7}$ cells $/ \mathrm{mL}$. The VX2 carcinoma was prepared in a $1 \mathrm{~mL}$ syringe with a $26 \mathrm{G}$ needle.

All rabbits were anesthetized with xylazine $(5 \mathrm{mg} / \mathrm{kg}$ intramuscularly; Rompun ${ }^{\mathrm{TM}}$, Bayer Korea Inc., Seoul, Korea) and alfaxalone $\left(5 \mathrm{mg} / \mathrm{kg}\right.$ intravenously; Alfaxan ${ }^{\circledR}$, Jurox Pty Ltd., NSW, Australia) to minimize suffering during all procedures. The abdominal hair of all 45 rabbits was shaved with a hair clipper. Then, the operating site was cleaned with $10 \%$ povidone iodine for a disinfection. The abdomen was opened with $5 \mathrm{~cm}$ incision site, and the lower thoracic esophagus was pulled into the abdominal cavity and exposed. The implantation site was approximately $5 \mathrm{~cm}$ away from the rabbit's stomach.

A $1 \mathrm{~mL}$ syringe needle was inserted into the muscular layer of the esophagus, and $100 \mu \mathrm{L}$ of VX2 cells was injected (Figure 1A). As soon as the syringe was removed, the injection site was pressed for about 30 seconds to prevent the VX2 cell from escaping. Next, the abdominal wall was closed and the wound was sterilized with $10 \%$ povidone iodine, and gentamicin $(2.5 \mathrm{mg} / \mathrm{kg})$ was injected into the muscles to prevent infection and ensure wound healing.

Two weeks after VX2 cells injection, tumor formation was evaluated using five randomly selected rabbits (number $1,3,12,26$, and 35 ) who received a $18 \mathrm{~F}$-fluorodeoxyglucose $\left({ }^{18} \mathrm{FDG}\right)$ positron emission tomography (PET) using a Gemini TF 16-slice PET scanner (Philips Medical Systems, Cleveland, OH, USA). All rabbits were fasted for at least $12 \mathrm{~h}$ before scanning and were anesthetized with xylazine and alfaxalone as described above. Each rabbit received $37 \mathrm{MBq}(1 \mathrm{mCi}){ }^{18} \mathrm{FDG}$ via an aurora vein, and chest PET images were obtained for 30 minutes. PET images were displayed and analyzed on a dedicated workstation (Extended Brilliance Workspace 3.5; Philips Medical Systems).

\section{Esophageal tumor detection in rabbits using ICG}

ICG (Daiichi-Sankyo Co., Tokyo, Japan) was administered at doses of 1,2 , or $5 \mathrm{mg} / \mathrm{kg}$ via the ear vein at $3,6,12,24$, or $48 \mathrm{~h}$ before surgery in rabbit esophageal cancer models. The fluorescence intensity in freshly excised esophageal tumor specimens was assessed using a custom-manufactured intraoperative color and fluorescence-merged imaging system (ICFIS), as previously described (13). The distance from specimens and camera was kept the same with $30 \mathrm{~cm}$ for all recordings. The ICFIS images of the esophageal 
A

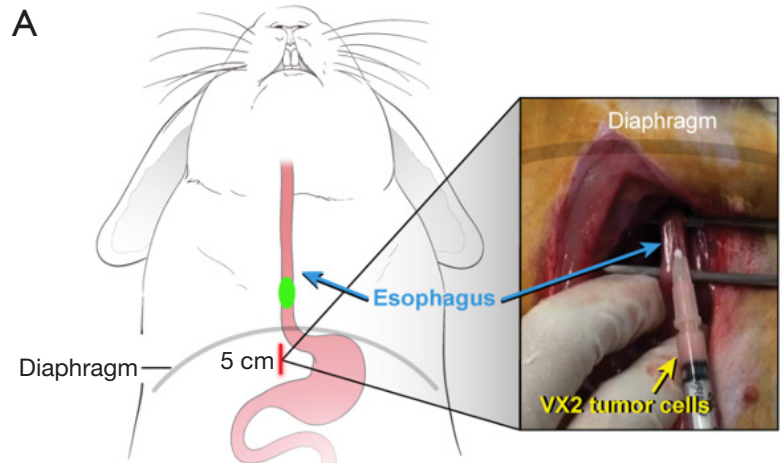

C Necropsy

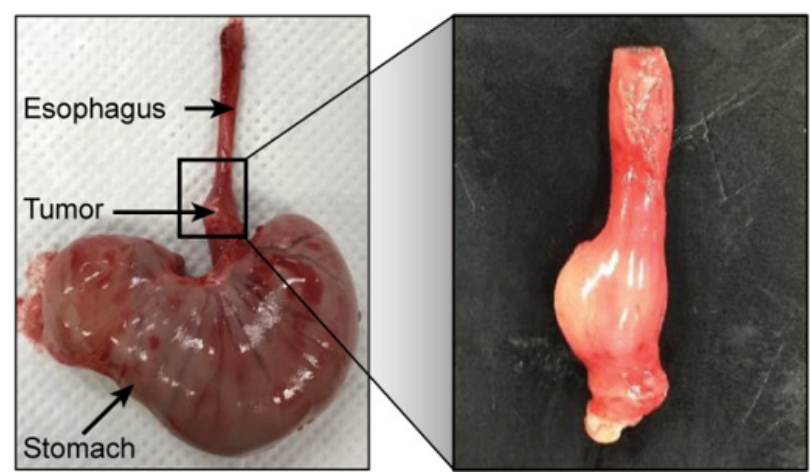

B

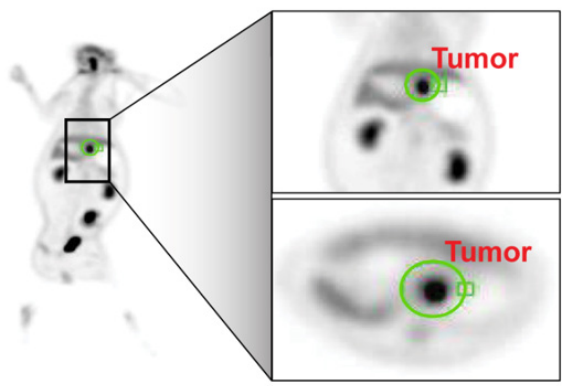

$H \& E$
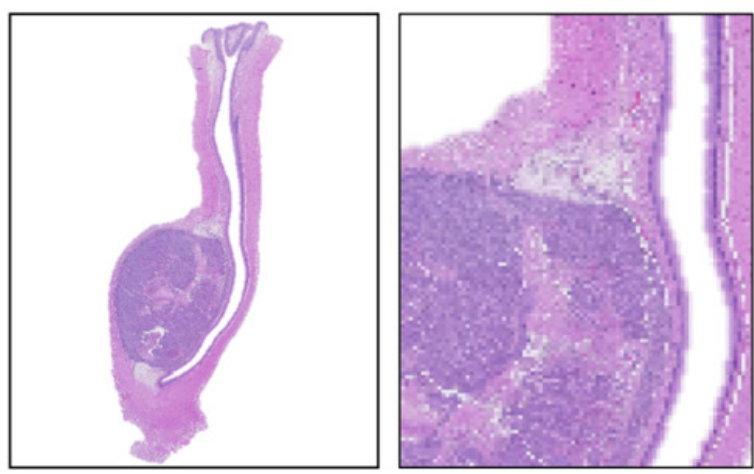

Figure 1 Establishment of the rabbit esophageal tumor model. (A) The method of the rabbit esophageal tumor model; injection of VX2 tumor cells in the lower esophagus through laparotomy; (B) esophageal tumor images on PET/CT scan 3 weeks after VX2 injection; (C) esophageal tumor formation on necropsy, and findings after H\&E staining. PET/CT, positron emission tomography/computed tomography.

tumor were used to measure a fluorescent intensity. Each intensity of a region of interest on the tumor and normal was measured using Image J software (64-bit Java 1.8.0_172, National Institute of Healthcare, Maryland, USA), and the signal of tumor-to-normal tissue ratio (TNR) was calculated. The signal greater than 1 means the intensity of tumor is higher than the normal, and the tumor has signal. Also, it can be easily distinguished the cancer and normal tissue by the fluorescent when the signal of TNR is higher than 2 (14). All specimens were evaluated by the experimenter as formalin-fixed and paraffin-embedded sections stained with hematoxylin and eosin (H\&E) and subsequently confirmed through pathology of the permanent sections in all cases.

\section{Patients}

Twelve patients who were scheduled for esophagectomy and gastric tube reconstruction for esophageal cancer between June 2015 and April 2020 at Korea University Guro Hospital were enrolled in this study. The study was conducted in accordance with the Declaration of Helsinki (as revised in 2013). The study was approved by institutional review board of Korea University Guro Hospital (No. 2020GR0181) and informed consent was taken from all the patients. The patients had been preoperatively diagnosed with esophageal cancer by esophagoscopic examinations, neck, thoracic, and abdominal computed tomography (CT), and positron emission tomography-computed tomography (PET-CT). Patients who had received neoadjuvant therapy were excluded from this study because of the possibility that the tumor would not remain after neoadjuvant therapy.

\section{Injection of ICG}

ICG (25 mg/vial, Daiichi Sankyo Co., Ltd., Tokyo, Japan) was dissolved in $10 \mathrm{~mL}$ of distilled water for injection, and an ICG dose of $2 \mathrm{mg} / \mathrm{kg}$ was administered intravenously 
to esophageal cancer patients at $3,6,12$, or $24 \mathrm{~h}$ before surgical removal of the esophagus.

\section{Surgical procedures}

All patients were intubated with a double-lumen endotracheal tube and positioned in the left lateral decubitus position during the thoracic procedures. Standard video-assisted thoracoscopic surgery is our routine procedure. For patients with middle and lower thoracic esophageal cancer (patient No. 1, 3, 4, 5, 6, 7, 8, 9, 10, 11, and 12), intrathoracic esophagogastrostomy was performed; in patients with upper thoracic esophageal cancer, esophagogastrostomy was performed through a left cervical incision (patient No. 2 and 3) (15). All esophageal cancers were removed leaving $8-10 \mathrm{~cm}$ or more from the proximal margin for complete resection, and esophagogastric anastomosis was performed using circular stapler anastomoses (EEA, Autosuture; U.S. Surgical Corp., Norwalk, CT, USA).

\section{Detection of esophageal tumors in buman specimens using a fluorescent imaging system}

After resection, all retrieved surgical specimens were incised to expose cancer and examined for fluorescent signals using the ICFIS. The TNR of the fluorescent signal was measured using Image J software. All specimens were sent to the pathology department to evaluate the tumor-nodemetastasis classification.

\section{Statistical analysis}

Descriptive data are presented as the mean \pm standard deviation. One-way analysis of variance was used to evaluate the correlation between fluorescence intensity and time or dose of ICG. Statistical significance was set at $\mathrm{P}<0.05$. Statistical analysis was performed using GraphPad program (Prism 8.3 software, GraphPad Software, San Diego, CA, USA).

\section{Results}

\section{Characteristics and fuorescence intensity of rabbit esophageal cancer}

Based on PET/CT images and necropsy, esophageal tumors were successfully established in all rabbits (Figure $1 B, 1 C$ ), and the mean tumor size was $0.86 \pm 0.21 \mathrm{~cm}$ (range, $0.5-1.3 \mathrm{~cm}$ ). Pathological results confirmed that the esophageal tumors grew well on the muscular layer of the rabbit esophagus (Figure 1C).

After injection of ICG with different doses of 1,2 , or $5 \mathrm{mg} / \mathrm{kg}$ via the ear vein in rabbit esophageal cancer models (Figure 2A), fluorescent signals were detected in all rabbits (Figure 2B). In particular, the fluorescence signal TNR values at $12 \mathrm{~h}$ before surgery showed the highest signal among different times with 1,2 , and $5 \mathrm{mg} / \mathrm{kg}$ of ICG. The fluorescent signal TNR increased over time, showing the highest signal at $12 \mathrm{~h}$ before surgery, followed by a decrease over time with all doses of ICG. The TNR value of $1 \mathrm{mg} / \mathrm{kg}$ of ICG at $12 \mathrm{~h}$ before surgery was too low to detect fluorescent signal $(1.36 \pm 0.01 ; \mathrm{P}=0.1016)$. The $\mathrm{TNR}$ value of $2 \mathrm{mg} / \mathrm{kg}$ of ICG was $2.81 \pm 0.04(\mathrm{P}=0.0001)$ and of $5 \mathrm{mg} / \mathrm{kg}$ of ICG was $3.33 \pm 0.17(\mathrm{P}=0.0001)$, and both fluorescent signals were sufficient to detect tumors with fluorescent signals (Figure 2C).

\section{Characteristics of esophageal cancer in patients}

Intravenous injection of ICG was performed in 12 patients (10 men and 2 women) (Table 1). The mean age of the patients was $65.3 \pm 6.0$ years (range, $57-79$ years). The mean tumor diameter was $4.5 \pm 1.4 \mathrm{~cm}$ (range, $1.7-6.5 \mathrm{~cm}$ ). Ten tumors were located in the middle thoracic esophagus and two were located in the lower thoracic esophagus. Two pathologists analyzed all the surgical specimens with the procedure as usual regardless of this study. Histological examination confirmed that all specimens were squamous cell carcinomas. There were no reported adverse effects related to the systemic injection of ICG, and no intraoperative events or bleeding were noted.

\section{Fluorescence intensity of esophageal cancer in patients}

All cases of esophageal cancer showed a higher NIR signal than surrounding normal tissues, and esophageal cancer was clearly detected with $2 \mathrm{mg} / \mathrm{kg}$ of ICG regardless of injection time (Figure 3A). The fluorescent signal TNR values increased over time; the highest signal was observed at $12 \mathrm{~h}(2.26 \pm 0.08 \mathrm{~h}, \mathrm{P}=0.0004)$ and decreased thereafter over time (Figure 3B). Therefore, ICG with $2 \mathrm{mg} / \mathrm{kg}$ at $12 \mathrm{~h}$ before surgery may be the optimal dosage and timing for detecting esophageal cancer.

\section{Discussion}

In this proof of concept study, the possibility of esophageal 

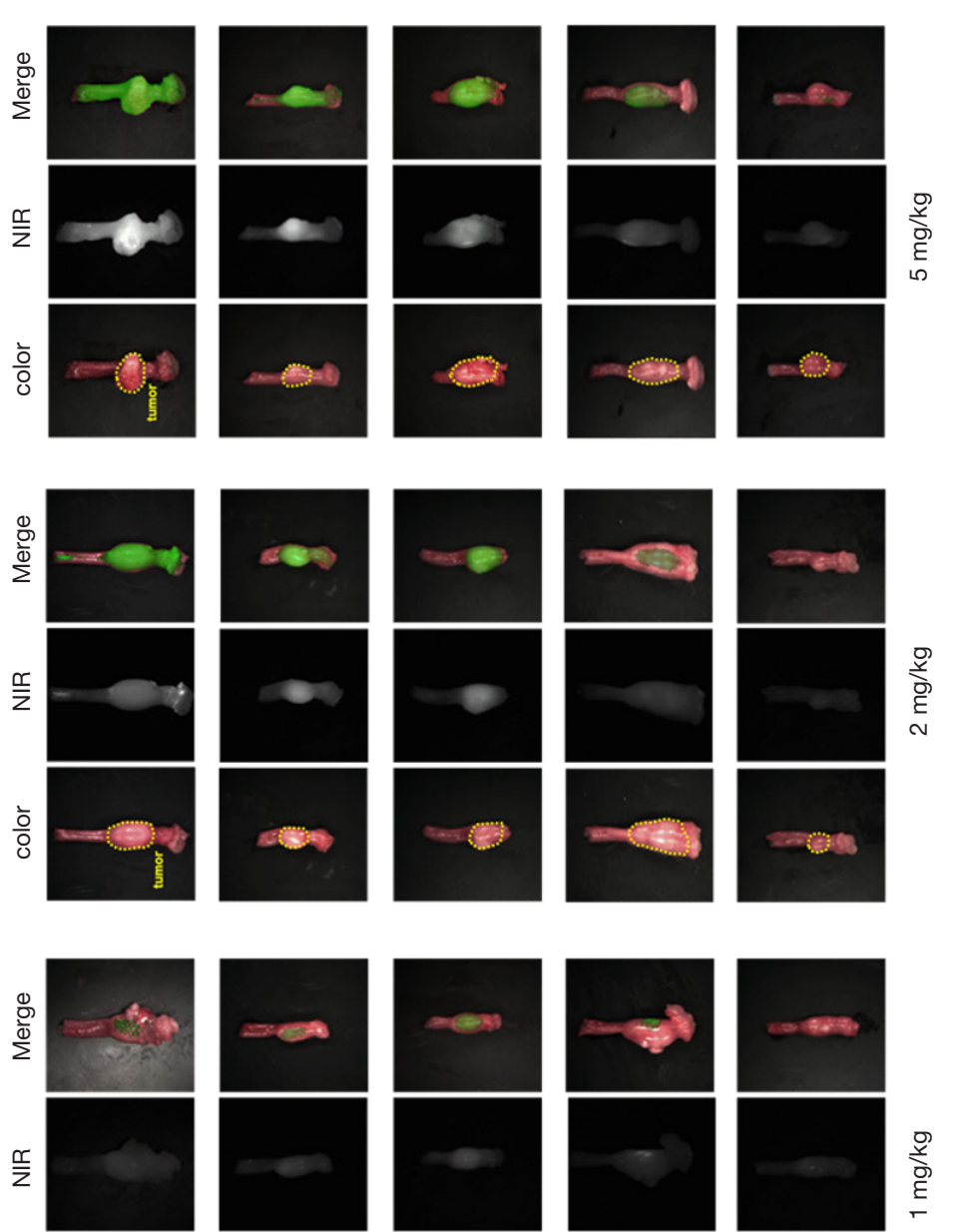

흥
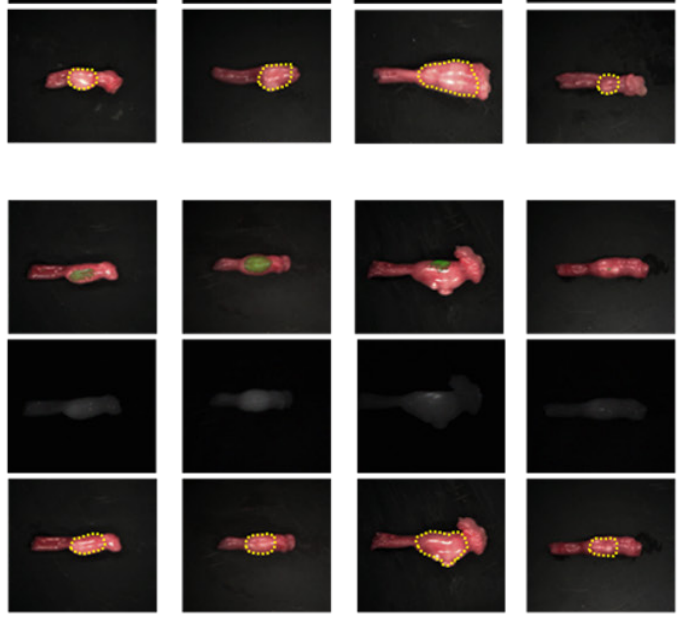

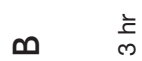
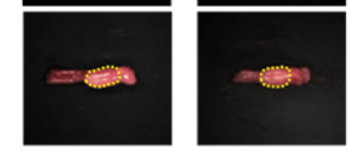

$\stackrel{亡}{\stackrel{2}{ }}$

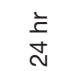

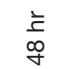
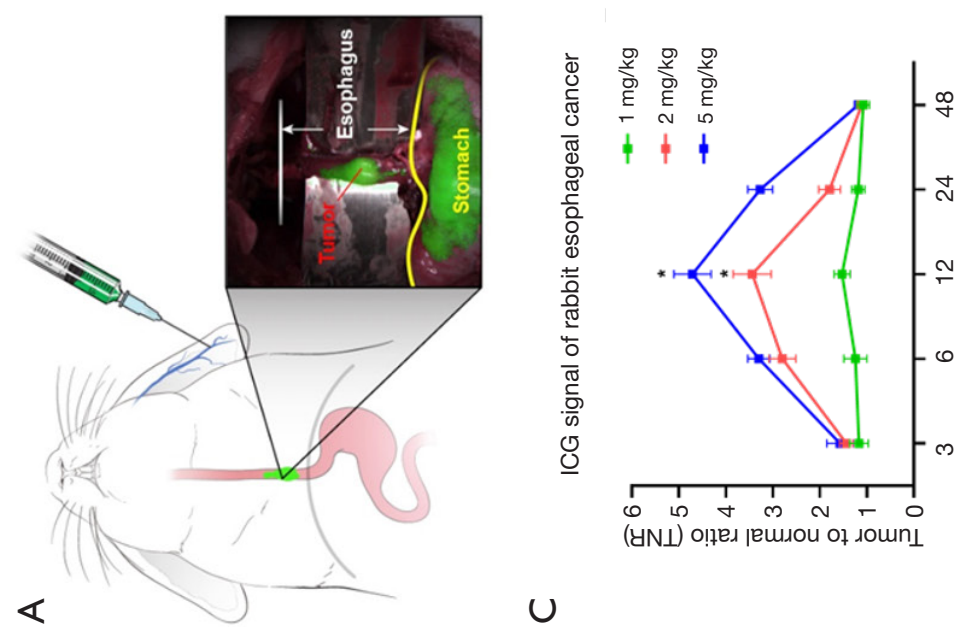

$\cup$

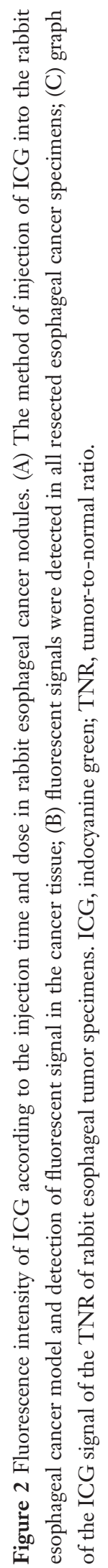


Table 1 Patient demographics and esophageal cancer characteristics

\begin{tabular}{|c|c|c|c|c|c|c|c|c|}
\hline $\begin{array}{l}\text { Patient } \\
\text { No. }\end{array}$ & Sex & $\begin{array}{l}\text { Age } \\
\text { (years) }\end{array}$ & $\begin{array}{l}\text { Tumor size } \\
\qquad(\mathrm{cm})\end{array}$ & Tumor location & $\begin{array}{l}\text { Time to imaging } \\
\text { (hours) }\end{array}$ & $\begin{array}{c}\text { The signal of } \\
\text { TNR }\end{array}$ & $\begin{array}{l}\text { Pathologic } \\
\text { staging }\end{array}$ & Surgical approach \\
\hline 1 & M & 67 & 1.7 & Middle of esophagus & 3 & 1.49 & pT1bNo & Intrathoracic esophagogastrostomy \\
\hline 3 & $\mathrm{~F}$ & 57 & 3.1 & Upper of esophagus & 3 & 1.63 & pT1bN1 & $\begin{array}{l}\text { Esophagogastrostomy through a left } \\
\text { cervical incision }\end{array}$ \\
\hline 4 & $\mathrm{~F}$ & 58 & 4.9 & Middle of esophagus & 6 & 2.07 & pT1bNo & Intrathoracic esophagogastrostomy \\
\hline 5 & M & 67 & 4.8 & Middle of esophagus & 6 & 2.43 & pT3NO & Intrathoracic esophagogastrostomy \\
\hline 6 & M & 64 & 6.5 & Middle of esophagus & 6 & 2.65 & pT3N1 & Intrathoracic esophagogastrostomy \\
\hline 7 & M & 63 & 5.1 & Middle of esophagus & 12 & 3.58 & pT3NO & Intrathoracic esophagogastrostomy \\
\hline 11 & M & 64 & 6 & Middle of esophagus & 24 & 1.9 & pT3N2 & Intrathoracic esophagogastrostomy \\
\hline 12 & M & 74 & 3.5 & Middle of esophagus & 24 & 1.65 & pT2NO & Intrathoracic esophagogastrostomy \\
\hline
\end{tabular}
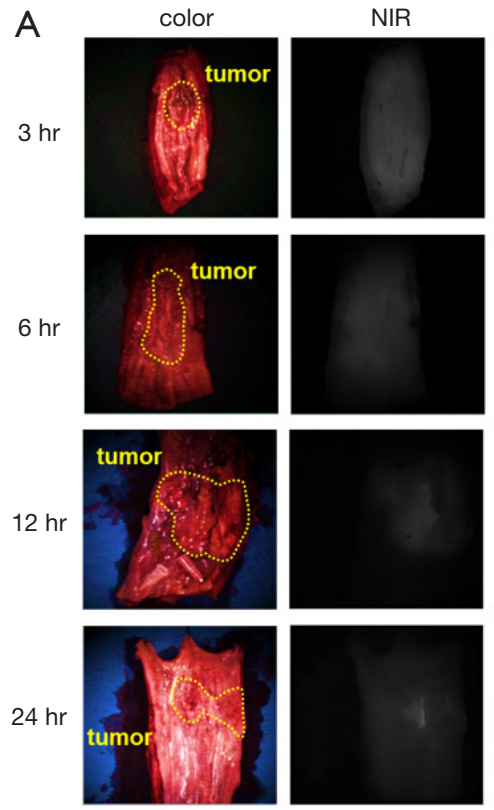

$2 \mathrm{mg} / \mathrm{kg}$
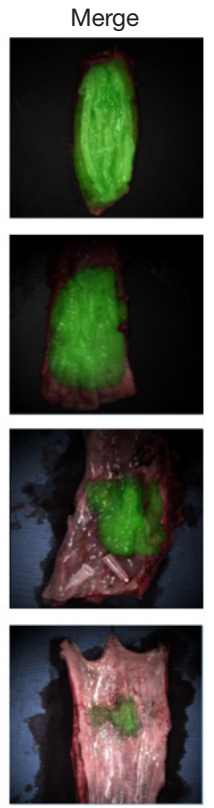

B ICG signal of the esophageal cancer specimens

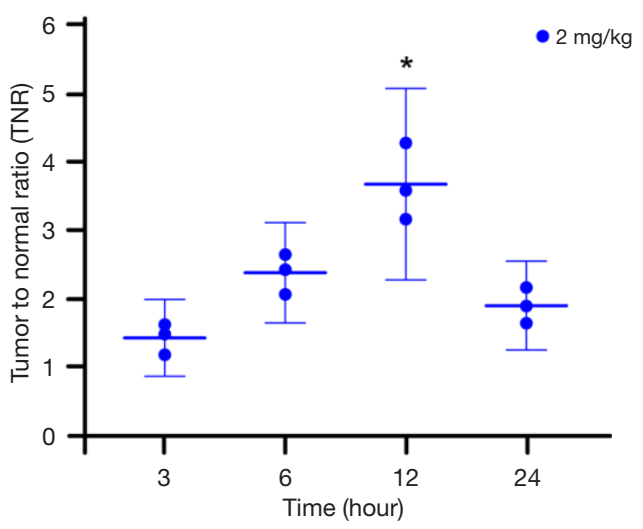

Figure 3 Fluorescence intensity of ICG at different time points after ICG injection in human specimens undergoing esophagectomy. (A) The fluorescence intensity in freshly excised esophageal tumor specimens was assessed using our custom-manufactured ICFIS. Fluorescent signals were detected in all resected esophageal cancer specimens. (B) graph of the ICG signal of the TNR of esophageal cancer specimens. ICG, indocyanine green; ICFIS, intraoperative color and fluorescence-merged imaging system; TNR, tumor-to-normal ratio. 
tumor detection with intravenous injection of ICG was evaluated for the first time. The optimal ICG injection doses and times of injection for the detection of esophageal tumors were additionally evaluated with a rabbit and human ex vivo specimens.

All esophageal cancers in the rabbits were successfully detected with all ICG doses used in this study. However, the TNR analysis showed that higher doses resulted in greater contrast between tumor and normal tissues. Our results indicate that $2 \mathrm{mg} / \mathrm{kg}$ of ICG is the most suitable dose for cancer detection because $1 \mathrm{mg} / \mathrm{kg}$ of ICG is not clearly visible and did not yield significant results with any of the injection times. The allergic reaction, such as anaphylaxis including a rash, itching, swelling of the face, tongue, and throat, trouble breathing or swallowing, or chest pain, after intravenous injection to the patient, frequency from ICG is reported to be $0.003 \%$ when the ICG concentration in the vein is less than $0.5 \mathrm{mg} / \mathrm{kg}$. However, the allergic reaction frequency is reported to increase significantly when the concentration exceeds $5 \mathrm{mg} / \mathrm{kg}$. Therefore, it would be better to use ICG with a minimum effective concentration (16). In the current study, the fluorescence signal TNR was the highest at $12 \mathrm{~h}$ after ICG injection at 1,2 , and $5 \mathrm{mg} / \mathrm{kg}$; therefore, we confirmed that ICG of $2 \mathrm{mg} / \mathrm{kg}$ at $12 \mathrm{~h}$ is the optimal injection method for tumor detection. In the different thoracic cancer surgery except esophageal cancer, they can be detected using $5 \mathrm{mg} / \mathrm{kg}$ of ICG intravenously injected $24 \mathrm{~h}$ prior to surgery using NIR fluorescent imaging (8-10). Also, our previous research of pulmonary neoplasms can be detected with $1 \mathrm{mg} / \mathrm{kg}$ of ICG at $24 \mathrm{~h}$ before (11). From animal data, our results also show that cancer is still detected when ICG with concentration of $5 \mathrm{mg} / \mathrm{kg}$ is injected at $24 \mathrm{~h}$ before the surgical resection. However, the ICG will be transferred to each internal organ through the blood stream, which it can be detected well at different times because of the different blood circulation times of each organ.

In addition, we identified the possibility of using fluorescence imaging for real-time detection of esophageal cancer during surgery in one patient (Figure S1). The fluorescent signal in the esophagus before resection was weak due to the depth limitation of ICG, which means that signals are not easily visible at depth of more than $2 \mathrm{~cm}$ of the tissue. However, the signal was sufficient to enable approximate localization of the cancer and distinguish the tumor from normal tissue. Further studies are needed to demonstrate the clinical use of ICG for intraoperative NIR imaging in a greater number of patients.
It is important to achieve a sufficient resection margin in esophageal cancer surgery. Although the minimum length of the proximal margin of esophageal cancer remains uncertain, it is recommended to leave more than $8 \mathrm{~cm}(17)$. Additionally, esophageal resection and reconstitution of gastrointestinal tracks across the neck, chest, and abdomen are considered very complex techniques (18). Therefore, if the cancer site is navigable through fluorescence signals in real-time during surgery, it can help surgeons to determine the optimal surgical approach, the optimal resection range to attain sufficient resection margins, and the surgical incision sites for reconstitution of the gastrointestinal tube. Further studies are needed to prove whether ICG helps provide the optimal surgical approach, the optimal resection range, and the surgical incision sites. For these results, there will be needed to compare the pathologic tumor border and the border by NIR fluorescent with ICG. Also, it is necessary to obtain results on whether NIR fluorescent signal with ICG could accurately identify the extent of intraepithelial spread.

Although this study was performed on different species and the variations in cancer sizes and types were limited, the study reported similar detection patterns in rabbit and human specimens. The optimal dose and injection time of ICG for the detection of esophageal cancer were reported for the first time through translational research. Although there will be needed more evidences, this may assist with the development of guidelines for the use of ICG in patients with esophageal cancer.

This study has several limitations. Cancer cannot be distinguished from inflammation using ICG since ICG is a passively distributed agent; a new agent that is able to target the cancer or result in stronger fluorescence needs to be developed. In addition, studies using fluorescent agents from the second NIR spectral window (NIR-II; wavelengths of 1,000-1,700 nm) that have higher resolution and allow a deep tissue fluorescence imaging than the first NIR spectral window (NIR-I; wavelengths of $650-900 \mathrm{~nm}$ ) are necessary to detect the submucosal tumor from the outside during surgery (19). And, although our results are helpful for clinical use, the power of the study is limited because of the small number of patients who have squamous cell carcinoma only involved and ex vivo specimens. Therefore, there is a need to conduct further research with larger patient populations regardless of the pathology and staging to optimize clinical use and analyze the correlation between pathology or stage and the intensity of fluorescence in the esophageal tumor. 
In this study, we successfully conducted detection of esophageal tumors with NIR fluorescent images by intravenous injection of ICG. By optimizing the injection time and dose of ICG, we found that intravenous injection of ICG $(2 \mathrm{mg} / \mathrm{kg})$ at $12 \mathrm{~h}$ before surgery could sufficiently detect esophageal tumors. If intraoperative tumor imaging is possible with ICG, it is useful in cancer surgery because it makes it easier for the surgeon to determine the location of the tumor during surgery so that the tumor can be controlled more accurately (20).

In conclusion, near-infrared fluorescence imaging could visualize esophageal cancer at $12 \mathrm{~h}$ after systemic injection of $2 \mathrm{mg} / \mathrm{kg}$ of ICG in both patients and a rabbit esophageal cancer model.

\section{Acknowledgments}

Funding: This research was supported by a grant from the Korea Health Technology R\&D Project through the Korea Health Industry Development Institute (KHIDI), funded by the Ministry of Health \& Welfare, Republic of Korea (grant number: HI15C3093 and HI17C0654).

\section{Footnote}

Reporting Checklist: The authors have completed the STROBE and ARRIVE reporting checklists. Available at https://dx.doi.org/10.21037/jtd-21-790

Data Sharing Statement: Available at https://dx.doi. org/10.21037/jtd-21-790

Peer Review File: Available at https://dx.doi.org/10.21037/ jtd-21-790

Conflicts of Interest: All authors have completed the ICMJE uniform disclosure form (available at https://dx.doi. org/10.21037/jtd-21-790). The authors have no conflicts of interest to declare.

Ethical Statement: The authors are accountable for all aspects of the work in ensuring that questions related to the accuracy or integrity of any part of the work are appropriately investigated and resolved. All animal experiments and protocols were approved by the institutional animal care and received committee approval from Korea University (KOREA-2016-0224). The study was conducted in accordance with the Declaration of
Helsinki (as revised in 2013). The study was approved by institutional review board of Korea University Guro Hospital (No. 2020GR0181) and informed consent was taken from all the patients.

Open Access Statement: This is an Open Access article distributed in accordance with the Creative Commons Attribution-NonCommercial-NoDerivs 4.0 International License (CC BY-NC-ND 4.0), which permits the noncommercial replication and distribution of the article with the strict proviso that no changes or edits are made and the original work is properly cited (including links to both the formal publication through the relevant DOI and the license). See: https://creativecommons.org/licenses/by-nc-nd/4.0/.

\section{References}

1. Bencini L, Moraldi L, Bartolini I, et al. Esophageal surgery in minimally invasive era. World J Gastrointest Surg 2016;8:52-64.

2. Tonutti M, Elson DS, Yang GZ, et al. The role of technology in minimally invasive surgery: state of the art, recent developments and future directions. Postgrad Med J 2017;93:159-67.

3. Vahrmeijer AL, Hutteman M, van der Vorst JR, et al. Image-guided cancer surgery using near-infrared fluorescence. Nat Rev Clin Oncol 2013;10:507-18.

4. Ishizawa T, Fukushima N, Shibahara J, et al. Real-time identification of liver cancers by using indocyanine green fluorescent imaging. Cancer 2009;115:2491-504.

5. Manny TB, Krane LS, Hemal AK. Indocyanine green cannot predict malignancy in partial nephrectomy: histopathologic correlation with fluorescence pattern in 100 patients. J Endourol 2013;27:918-21.

6. Altino lu EI, Russin TJ, Kaiser JM, et al. Nearinfrared emitting fluorophore-doped calcium phosphate nanoparticles for in vivo imaging of human breast cancer. ACS Nano 2008;2:2075-84.

7. Keating J, Tchou J, Okusanya O, et al. Identification of breast cancer margins using intraoperative near-infrared imaging. J Surg Oncol 2016;113:508-14.

8. Okusanya OT, Holt D, Heitjan D, et al. Intraoperative near-infrared imaging can identify pulmonary nodules. Ann Thorac Surg 2014;98:1223-30.

9. Kennedy GT, Newton A, Predina J, et al. Intraoperative near-infrared imaging of mesothelioma. Transl Lung Cancer Res 2017;6:279-84.

10. Predina JD, Keating J, Newton A, et al. A clinical trial of 
intraoperative near-infrared imaging to assess tumor extent and identify residual disease during anterior mediastinal tumor resection. Cancer 2019;125:807-17.

11. Kim HK, Quan YH, Choi BH, et al. Intraoperative pulmonary neoplasm identification using near-infrared fluorescence imaging. Eur J Cardiothorac Surg 2016;49:1497-502.

12. Choi BH, Young HS, Quan YH, et al. Real-time computed tomography fluoroscopy-guided solitary lung tumor model in a rabbit. PLoS One 2017;12:e0179220.

13. Oh Y, Quan YH, Choi Y, et al. Intraoperative combined color and fluorescent images-based sentinel node mapping in the porcine lung: comparison of indocyanine green with or without albumin premixing. J Thorac Cardiovasc Surg 2013;146:1509-15.

14. Quan YH, Oh CH, Jung D, et al. Evaluation of Intraoperative Near-Infrared Fluorescence Visualization of the Lung Tumor Margin With Indocyanine Green

Cite this article as: Rho J, Quan YH, Choi BH, Han KN, Kim BM, Choi YH, Kim HK. Near-infrared fluorescent imaging with indocyanine green in rabbit and patient specimens of esophageal cancer. J Thorac Dis 2021;13(11):6314-6322. doi: 10.21037/jtd-21-790
Inhalation. JAMA Surg 2020;155:732-40.

15. Kim HK, Choi YH, Shim JH, et al. Endoscopic evaluation of the quality of the anastomosis after esophagectomy with gastric tube reconstruction. World J Surg 2008;32:2010-4.

16. Speich R, Saesseli B, Hoffmann U, et al. Anaphylactoid reactions after indocyanine-green administration. Ann Intern Med 1988;109:345-6.

17. Allum WH, Bonavina L, Cassivi SD, et al. Surgical treatments for esophageal cancers. Ann N Y Acad Sci 2014;1325:242-68.

18. Raymond D. Complications of esophagectomy. Surg Clin North Am 2012;92:1299-313.

19. Choi HS, Kim HK. Multispectral image-guided surgery in patients. Nat Biomed Eng 2020;4:245-6.

20. Chi C, Du Y, Ye J, et al. Intraoperative imaging-guided cancer surgery: from current fluorescence molecular imaging methods to future multi-modality imaging technology. Theranostics 2014;4:1072-84. 


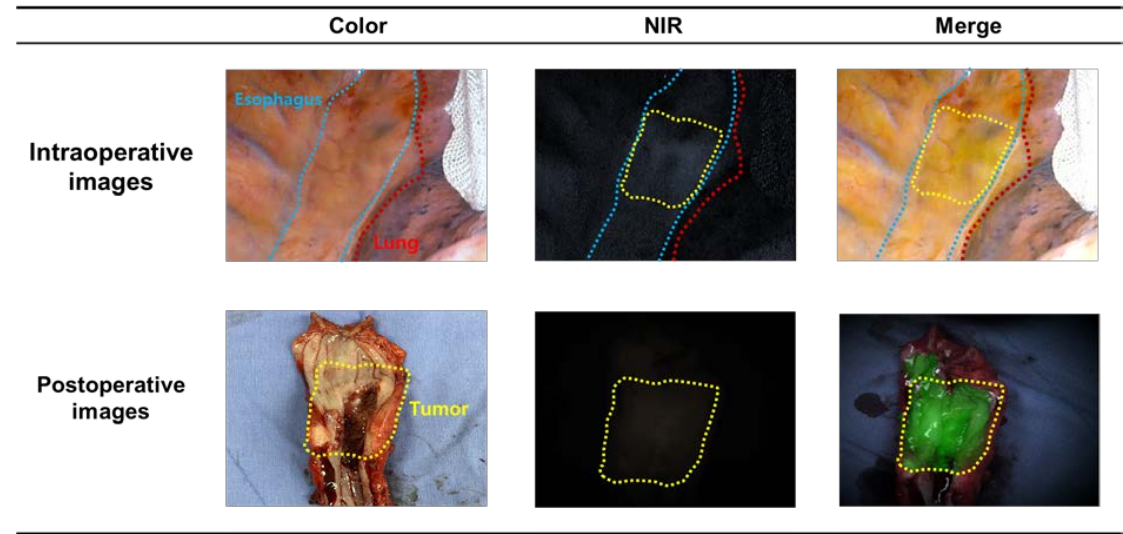

Figure S1 Fluorescence signal in the esophageal cancer during and after surgery. 